\title{
IoT Based Energy Meter with Theft Detect
}

\author{
M.V. Ramesh, P.Sowjanya
}

\begin{abstract}
The idea of this paper is to have energy meter design using IoT (Internet of Things) and implementing based on microcontroller. The buyer has the possibility of pre paying/ post paying the electricity usage on schedule. If not paid, the utility centres can switch off the supply remotely. The monitoring of the electrical energy consumption can be made easy by the customer on their mobile/PC.Power theft is detected by using current sensors. Theft detected will be notified on service provider end. The IoT operation is performed by Wi-Fi unit. The meter data is send to webpage that can be accessed from IP address. IoT has made a virtual network between the human and this physical world and has drastically changed the way business works. This can be accomplished by sending the ideal stage between the gadgets for data transmission. In this paper, IoT technology is utilized in distribution system to detect the power theft.
\end{abstract}

Keywords: IoT, Energy meter, Microcontroller, WIFI, Power theft.

\section{INTRODUCTION}

To reduce the human errors and labour cost in energy consumption efficiently, IoT's energy monitoring for power management is considered [1]. Electrical power theft is a regular practice in creating nations which can't be constrained by the administrations because of absence of innovation [2]. A energy meter with prepaid system for theft control was also proposed [3]. In present days, with the enhancement of IoT and digital technologies, smart grid has been attractive smarter than before [4].The advancement of power theft identification and preventive actions of the system by using IoT innovation is presented [5]. An integrated Web Server allows collecting the statistics, interfacing the devices for load displacement [6]. It depends on an energy meter with little power micro controller [7]. This model configuration intimates about the Theft identification, power utilization and energy control. [8]. IoT has made a virtual network between the human and this physical world and has drastically changed the way business works [9]. These automated systems provide accuracy in billing and also enables the consumers to do power optimization [10]. The output of this paper is a practical IoT based scheme that is able to recognize tamper and cut-off the user.

The paper is organized as follows. Different types of energy meters and applications are mentioned in section2. The details of Microcontroller are mentioned in Section 3.
Different types of communication links are presented in Section 4. Hardware description and their parts are clarified in Section 5.The Conclusions are exhibited in Section 6.

\section{ENERGY METER}

The power energy utilized by the customers is measured by energy meter and the unit is KWH. The instantaneous voltage and current is being measured by the meter and their product gives instantaneous power. The instantaneous power incorporated in one hour or over period provides the total electrical energy utilized by the customer.

These instruments installed at the consumers might be 1- $\phi$ or 3- $\phi$ meters relying upon the measure of energy used. For the customers utilizing less amount of energy the energy meter can be introduced directly in the middle of the line and load. The customers having bigger loads a current transformer and/or potential transformer are to be connected to isolate energy meters from higher currents.

Energy meter is classified as electromechanical type, Electronic type and Smart Energy Meters.

\section{MICROCONTROLLER}

Microcontrollers are "particular functional computers". Microcontrollers are "embedded" inside with other instrument so that they can control the characteristics or operations of device. In other words microcontroller is also called as "embedded controller". The microcontroller is usually small in size \& minimal price. The parts are preferred to reduce size and economical as could be expected under the circumstances. A microcontroller is regularly, however not all the time, rugged in nature somehow or another.

AT89S52 is low power, incredible execution CMOS 8-bit microcontroller with $8 \mathrm{~K}$ bytes of in-approach programmable Flash memory. The instrument is made using Atmel's high-thickness non-unstable memory advancement and is great with the business standard 80C51 guidance set and pin out. The on-chip Flash enables the program memory to be recreated in-approach or by a customary non-unstable memory software engineer. By adding 8-bit CPU with in-approach programmable Flash on a solid chip, the Atmel AT89S52 is an incredible microcontroller which gives an entirely adaptable and insignificant cost answer for most embedded control applications. 


\section{COMMUNICATION DEVICES}

The ESP8266 is a minimal cost microchip and microcontroller that enables microcontrollers to interface with a Wi-Fi system and build basic TCP/IP links utilizing Hayes-style commands. The external components on the module which are recommended to be extremely reasonable in volume, attracted in numerous hackers to investigate the module, chip, and the software used to translate the documentation from China.

The ESP8285 (ESP8266) having $1 \mathrm{MB}$ of integrated flash, taking into consideration for single-chip devices able to interface with Wi-Fi. Passive labels assemble power from a nearby RFID. Active labels have a close-by power source, and many meters from the RFID reader.

RFID labels are utilized in numerous industries, for example, an RFID tag joined to a car during generation can be utilized to track its development through the assembly line; RFID-tagged pharmaceuticals can be followed through distribution centers; and embedding RFID microchips in domesticated animals and pets takes into account for positive identification of creatures.

Bluetooth is a remote technology for information transfer over short distances from any electronic gadgets. Created by telecom seller Ericsson in 1994 it was initially imagined as a remote option in contrast to RS-232 information data links.

Zigbee is a high level communication protocols with IEEE specification utilized to communicate with personal area networks by means of little, low-energy digital radios, for example, medicinal device information and additional low-control \& bandwidth capacity needs. The skill characterized by the Zigbee is planned with less difficult and more affordable than different wireless personal area networks (WPANs). Its low power use of transmission limits are 10- 100 meters depends on the power output and environmental conditions. It has a specific rate of $250 \mathrm{kbit} / \mathrm{s}$, most proper for discontinuous information data transmissions from a sensor or input device.

RF module (radio frequency module) is a (generally) little electronic instrument used to transmit as well as get radio signals between two equipments. In an embedded system it is usually desirable to communicate with another device remotely. This wireless communication might be cultivated through optical communication or through radio frequency (RF) communication.

IoT is associated with physical items that are open through the internet. It could be an individual with a heart monitor or a car with built-in- sensors. The technology of embedded system helps them to associate with internal positions or the outside condition, which thus influences the choices taken.

IoT can connect devices embedded in different systems to the internet. Whenever devices/items can represent themselves digitally, they can be controlled from anyplace. The performance of companies can be improved through IoT analytics and IoT Security to deliver better results. Organizations in the use, protection, producing, trade sector can receive rewards of IoT by settling on additional choices, supported through value-based information available to them.

\section{HARDWARE DESCRIPTION}

Block diagram of IoT appeared in Fig. 1. Software part of IoT device is responsible for device behavior and written in the microcontroller stage.

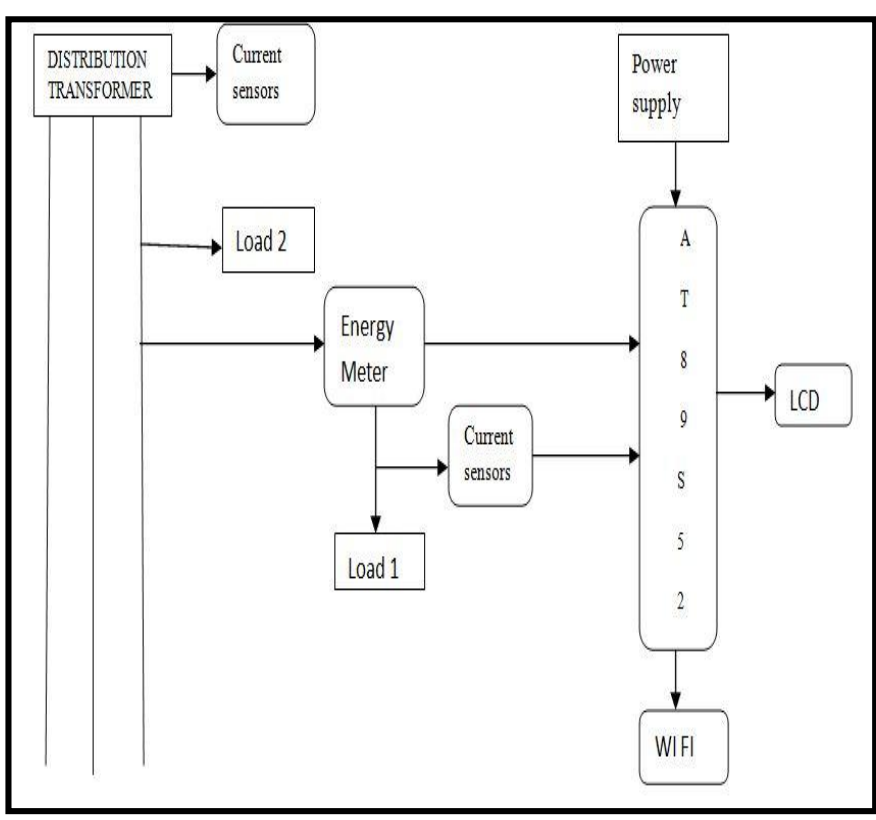

Fig. 1: System Block Diagram

\section{A.Hardware components}

\section{MICROCONTROLLER \\ MCP3208 IC \\ POWER SUPPLY CIRCUIT \\ CRYSTAL OSCILLATOR \\ MODULE \\ LCD DISPLAY}

CURRENT SENSOR

ESP8266 Wi-Fi

The MCP3208 features 100k sample/second, 8 input channels, low power utilization and is available in 16-pin PDIP and SOIC packages.

The input $230 \mathrm{~V}$ is step down to $12 \mathrm{~V}$ by using step down transformer and is fed to a rectifier. Transformer output is given to the rectifier. The rectifier changes $\mathrm{AC}$ into pulsating DC. In this paper, a bridge rectifier is used to get enormous stability and full wave rectification.

Capacitive filter removes the ripples from the rectifier and smoothens the DC output. The filter is consistent until the mains voltage and load is maintained steady. At any case, if both of the two is varied, DC voltage also changes. So, the regulator is connected at the output stage. The Supply block diagram is shown in Fig. 2.

A voltage regulator is an electrical regulator expected to consequently maintain a constant voltage level. In this paper, control supply of $5 \mathrm{~V}$ and $12 \mathrm{~V}$ are required. So as to get these voltage levels, 7805 and 7812 voltage controllers are to be used. 
Detecting and controlling current flow is necessity in a wide variety of uses including, over-current production circuits, battery chargers, switching mode control supplies, advanced watt meters, programmable current sources, and so forth.

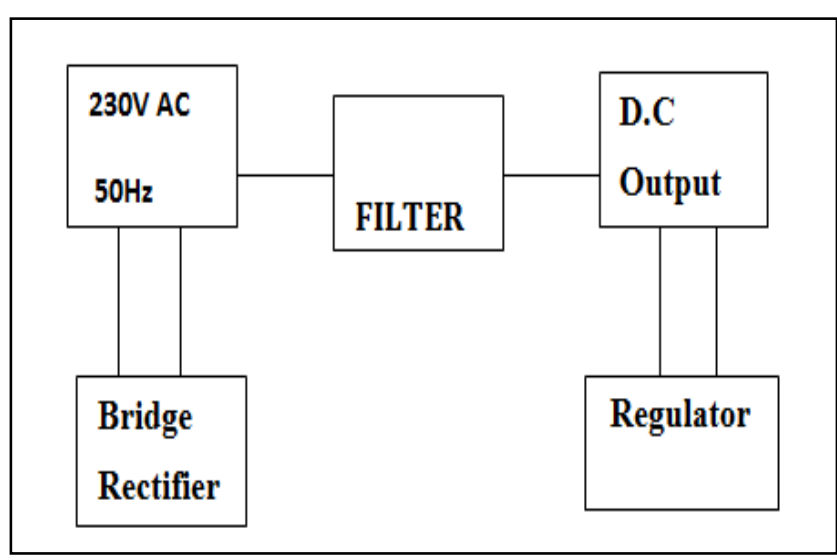

Fig. 2: Block diagram of supply

This ACS721 current module depends on ACS712 sensor, which can precisely identify AC or DC current. The most extreme $\mathrm{AC}$ or $\mathrm{DC}$ that can be distinguished can reach $5 \mathrm{~A}$, and the present current signal can be read by means of simple I/O port of Arduino.

The block diagram of the system and mode of operation is represented in Fig. 3.

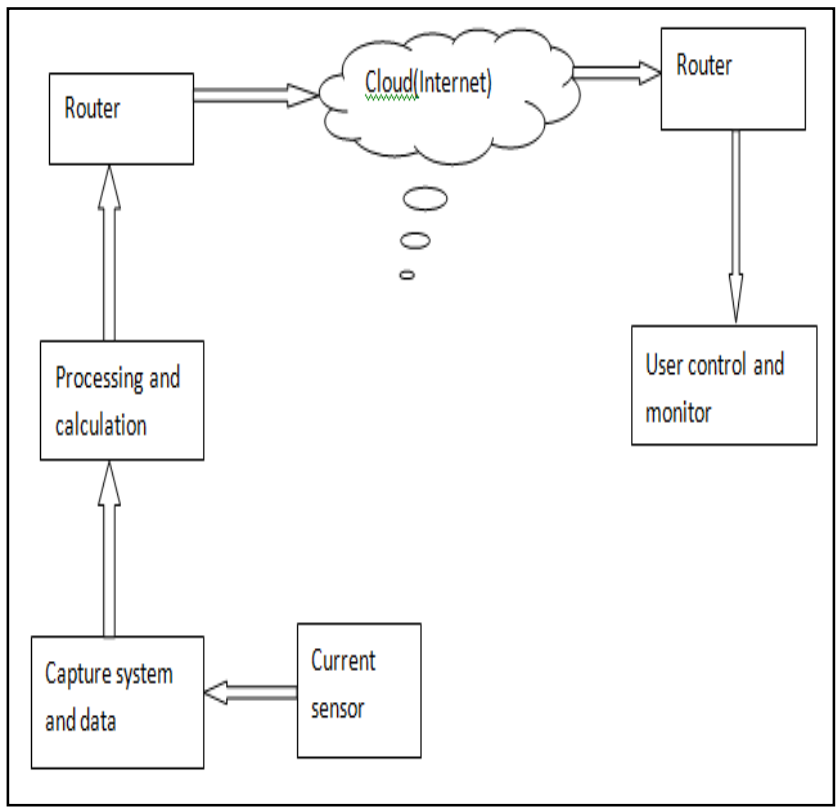

Fig. 3: Block diagram of system

$\mathrm{I}^{2} \mathrm{~S}$ (Inter-IC Sound), well-defined eye-squared-ess is utilized to communicate PCM audio data information between integrated circuits in electronic equipment. The $\mathrm{I}^{2} \mathrm{~S}$ bus isolates clock and serial data signals which helps in recover the clock from the information stream. Despite the name, $\mathrm{I}^{2} \mathrm{~S}$ is inconsequential to the bidirectional $\mathrm{I}^{2} \mathrm{C}$ (IIC) bus.

The electric signalling dimensions and strategies are taken care of by a driver circuit external peripheral to the UART.A UART is generally an entity integrated circuit (IC) utilized for serial communication over a pc or peripheral device sequential port. UARTs are ordinarily incorporated into microcontrollers.

Both the CPU and flash clock speeds can be able to multiply by over timing on a few devices. CPU can be operated at $160 \mathrm{MHz}$ and flash can be accelerated from 40 $\mathrm{MHz}$ to $80 \mathrm{MHz}$ Achievement changes chip to chip.

LCD Display units are the most essential output devices in embedded tasks and electronics products. 16x2 LCD is most utilized display unit. 16x2 LCD implies that there are two rows in which 16 characters can be displayed per line, and each character consumes $5 \times 7$ matrix space on LCD.

The algorithm explains the system operation and theft detection is represented as flowchart in Fig. 4.

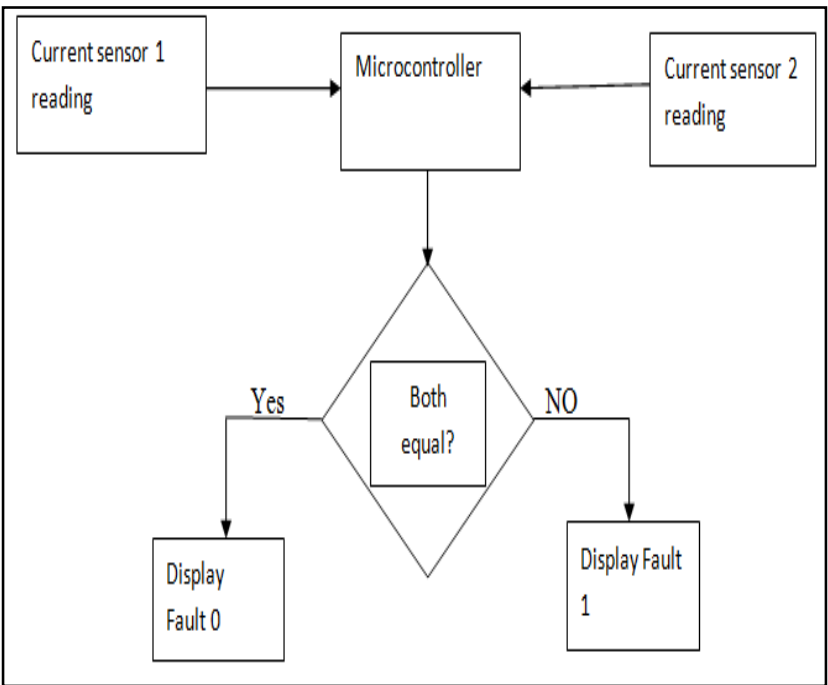

Fig. 4: Flow chart for theft detection

In fig. 5, LCD display with units consumed by different home appliances and present temperature of the house is displayed.

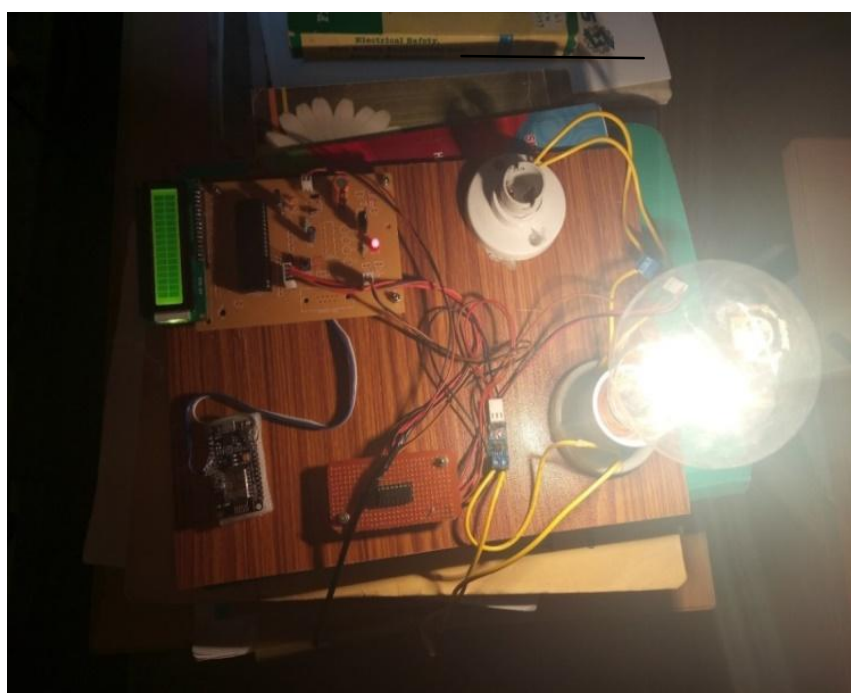

Fig. 5: Load acting without power theft

Fig. 6 show the snapshot of IoT energy meter which displays the mobile application without power theft of the system. 


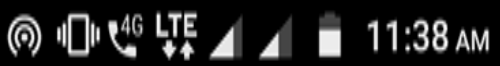
Screen 1

\section{IOT ENERGY METER}

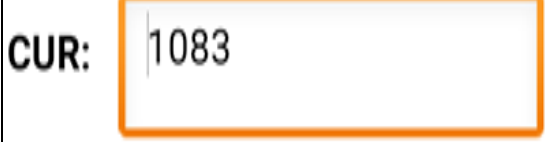

FAULT 0

Fig. 6: Display on mobile application without power theft

In fig. 7 LCD display with units consumed by different home appliances and present temperature of the house along with theft detection is displayed.

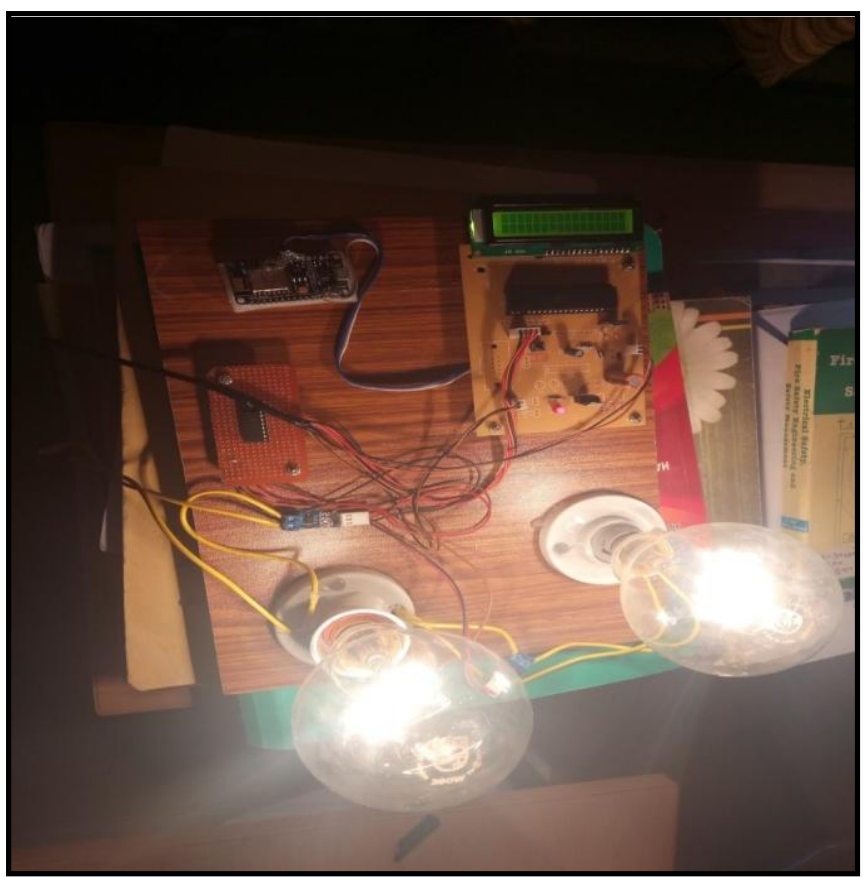

Fig. 7: Load along with theft load

Fig. 8 show the snapshot of IoT energy meter which displays the mobile application during power theft of the system.

\section{$\triangle$}

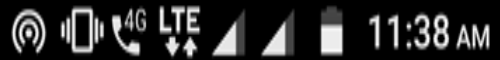

\section{Screen 1}

IOT ENERGY METER

CUR:

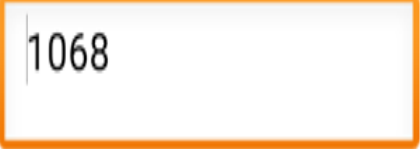

FAULT

\section{1}

Fig. 8: Display on mobile application during power theft

\section{CONCLUSION}

This paper mainly presents the IoT based energy meter system along with theft detection and presenting related IoT models to make a smart meter as a part of the future vision of power billing. In this work we represented an Energy measuring system that is able to be monitored all over the world using internet. Finally, the implemented model demonstrated that it can control the appliances from mobile. It is easy to monitor the current and power. It provides continuous monitoring and detects power theft. Due to continuous monitoring we can reduce the wastage of energy. It can be used in power distribution systems to reduce power thefts.

The disadvantage of this examination is the absence of accessible information in that blocks the required experimental investigation on advantages of IoT innovation and cyber security is the greatest obstacle.

\section{REFERENCES}

1. Win Hlaing, Somchai Thepphaeng, Varunyou Nontaboot, Natthanan Tangsunantham, Tanayoot Sangsuwan, Chaiyod Pira. Implementation of WiFi-Based Single Phase Smart Meter for Internet of Things (IoT) .5th IEEE Congress, Pattaya, Thailand, 8-10 March 2017.

2. Dineshkumar.K,Prabhu Ramanathan, Sudha Ramasamy.Development of ARM Processor based Electricity Theft Control System using GSM Network. International Conference on Circuit, Power and Computing Technologies [ICCPCT], 2015.

3. Nabil Mohammad, Anomadarshi Barua and Muhammad Abdullah Arafat.A Smart Prepaid Energy Metering System to Control Electricity Theft.2013 International Conference on Power, Energy and Control (ICPEC).

4. Mohammad Hossein Yaghmaee,Hossein Hejazi.Design and Implementation of an Internet of Things Based Smart Energy Metering.2018 the 6th IEEE International Conference on Smart Energy Grid Engineering.

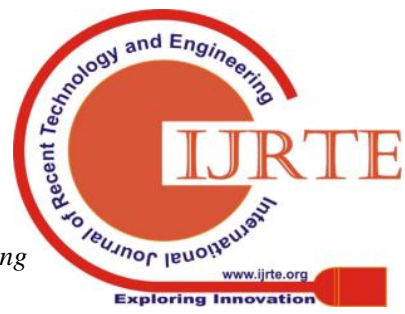


5. R. E. Ogu and G. A. Chukwudebe,Development of a Cost-Effective Electricity Theft Detection and Prevention System based on IoT Technology.2017 IEEE 3rd International Conference on Electro-Technology for National Development (NIGERCON).

6. Landi.C.; Dipt.diIng.dellInf., SecondUniv.diNapoli, Aversa,Italy; Merola,p.; Ianniello,G, ARM -based energy management system using smart meter and webserver, IEEE Instrumentation and measurement Technology conference Binjiang, pp.1-5, May 2011.

7. Garrab,A.;Bouallegue,A.;Ben Abdallah, A new AMR approach for energy saving in smart grids using smart meter and power line communication,IEEE first conference on Renewable energies and vehicular Technology(REVET),pp.263-269, march 2012.

8. B.Ravali, R.P.ManikantaKumar, V.Aditya, CH.Amrutha, N.Veeraiah,IoT Based Energy Meter Reading, Theft Detection and Energy Control Using GSM ,International Journal of Engineering Research in Computer Science and Engineering (IJERCSE) Vol 5, Issue 3, March 2018.

9. Srujana Uddanti, Christeena Joseph, P.C.Kishoreraja.IoT Based Energy Metering and Theft Detection.International Journal of Pure and Applied Mathematics Volume 117 No. 9 2017, 47-51.

10. Dr. S.S. Sayyed, Roshani Choudhari, Prashant Tribhuvan, Sagar Salvi, Anuradha Amte Theft Detection and Disconnection in Automated Electricity Energy Meter: A Survey Internal (IJRASET) ISSN: Volume 6 Issue I, January 2018.

\section{AUTHORS PROFILE}

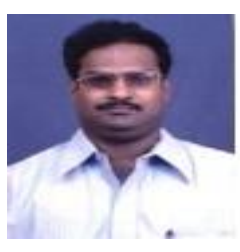

M.V.Ramesh received the B.Tech degree in Electrical and Electronics Engineering from Nagarjuna University in the year 1998, M.S (Electrical Engineering) from German university in the year 2002 and Ph.D in the area of Industrial Drives from Jawaharlal Nehru Technological University Hyderabad. Presently he is working as an Associate Professor at Prasad V. Potluri Siddhartha Institute of Technology, Vijayawada. His research interests include Power electronics and drives, Power Electronics, Industrial Drives and automation, Hybrid Vehicle Design Renewable Energy Sources, Optimisation Techniques and Reactive power compensation. He has about 30 papers in the national and international journals and conferences.

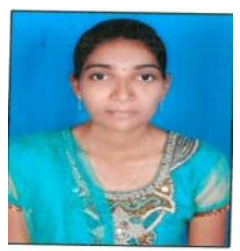

Sowjanya P. received the B.Tech degree in electrical engineering from the Andhra Loyola institute of engineering in 2017. She is currently pursuing the M.Tech degree with the Department of Electrical Engineering, PVP Siddhartha Institute of Technology in the City of Vijayawada. Her current research interests are in power systems, smart grid and renewable energy systems. 